
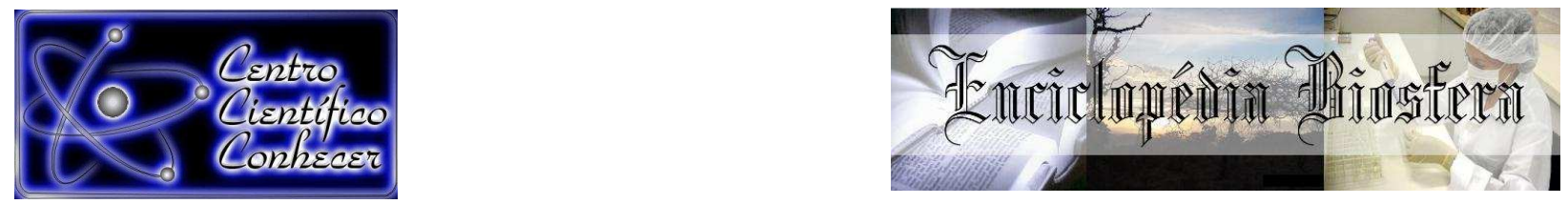

\title{
AVALIAÇÃO DA ATIVIDADE ANTIMICROBIANA DAS ESPÉCIES Aspidosperma nitidum, Annona crassiflora e Annona mucosa FRENTE A CEPAS ATCC
}

Tâmila Siminski $1^{*}$, Jaqueline Sampietro de Souza ${ }^{1}$, Cristiane Ferreira Lopes de Araujo $^{2}$, Rogério Benedito da Silva Añez ${ }^{2}$, Rogerio Alexandre Nunes ${ }^{3}$

${ }^{1}$ Graduando em Ciências Biológicas. Centro de Pesquisa, Estudos e Desenvolvimento Agro-Ambiental, Universidade do Estado de Mato Grosso, Tangará da Serra-MT, Brasil. e-mail: *tamilasiminski@gmail.com

${ }^{2}$ Professor(a) doutor(a) do curso de Ciências Biológicas. Centro de Pesquisa, Estudos e Desenvolvimento Agro-Ambiental, Universidade do Estado de Mato Grosso, Tangará da Serra-MT, Brasil.

${ }^{3}$ Professor doutor do curso de Enfermagem. Centro de Pesquisa, Estudos e Desenvolvimento Agro-Ambiental, Universidade do Estado de Mato Grosso, Tangará da Serra-MT, Brasil.

Recebido em: 08/09/2015 - Aprovado em: 14/11/2015 - Publicado em: 01/12/2015 DOI: http://dx.doi.org/10.18677/Enciclopedia_Biosfera_2015_008

A bioprospecção de novas moléculas é de grande importância devido a limitação quanto à eficácia ou toxicidade dos principais agentes terapêuticos disponíveis para o tratamento de doenças. Nos últimos anos, o uso indiscriminado de antibióticos levou os microrganismos a desenvolverem resistência, fazendo-se necessárias novas tecnologias. Deste modo, as plantas medicinais nativas vêm sendo um dos principais meios para a busca de substâncias bioativas. $O$ presente trabalho objetivou avaliar o potencial antibacteriano dos extratos de Aspidosperma nitidum, Annona crassiflora e Annona mucosa, frente a Cepas de Staphylococus aureus ATCC $\AA$ 25923, Escherichia coli ATCC $\AA 25922$ e Pseudomonas aeroginosa ATCC $\AA$ 27853. O extrato de cada planta foi diluído em concentrações de 1:2, 1:4, 1:8, 1:16, 1:32. De cada cepa bacteriana foram selecionadas três a quatro colônias, as quais foram transferidas para tubo de ensaio contendo solução $\mathrm{NaCl}$, sendo submetidas a diluição seriada para obter uma carga de microrganismo de 10-8 UFC/mL, e incubados a $35^{\circ} \mathrm{C}$ por cinco horas. Cada um dos três microrganismos foi submetido aos três extratos sendo cinco tratamentos por extrato com cinco repetições, de cada concentração dos extratos. Com o auxilio de um paquímetro foram realizadas as aferições dos halos de inibição de crescimento bacteriano. Considerando inibição da atividade microbiana as soluções que apresentaram diâmetros superiores a $8 \mathrm{~mm}$. Os extratos das três plantas apresentaram resultados satisfatórios no controle dos três organismos. O extrato de Annona mucosa apresentou em todos os organismos analisados valores inibitórios médios superiores a dos demais extratos. Todos os extratos utilizados neste estudo demonstraram grandes potenciais antimicrobianos.

PALAVRAS-CHAVE: Medicinal, Nativas, Plantas, Resistência. 


\title{
EVALUATION OF THE ANTIMICROBIAL ACTIVITY OF THE SPECIES ASPIDOSPERMA NITIDUM, ANNONA CRASSIFLORA AND ANNONA MUCOSA FRONT TCC STRAINS
}

\begin{abstract}
The biopanning of new molecules is of great importance due to the limitation on the efficacy or toxicit of the main therapeutic agents available for the treatment of diseases. In recent years, the indiscriminate use of antibiotics has led microorganisms develop resistance, making it necessary new technologies. Thus, the native medicinal plants have been a key means for the pursuit of bioactive substances. This study aimed to evaluate the antimicrobial activity of extracts Aspidosperma nitidum, Annona crassiflora and Annona mucosa, against strains Staphylococcus aureus ATCC® 25923, Escherichia coli ATCC® 25922 and Pseudomonas aeruginosa ATCC® 27853. The extract was diluted in each plant concentrations of $1: 2,1: 4,1: 8,1: 16,1: 32$. Of each bacterial strain were selected 3 to 4 colonies, which were transferred to test tubes containing $\mathrm{NaCl}$ solution, and subjected to serial dilution to obtain a microorganism load UFC/ml 10-8, and incubated at $35^{\circ} \mathrm{C}$ for 5 hours. Each of the three mi cro-organism has been subjected to the three extracts and extract five treatment with 5 replicates for each concentration of the extracts. With the aid of a caliper measurements were performed halos of inhibition of bacterial growth. Whereas inhibition of microbial activity the solutions presented diameters greater than $8 \mathrm{~mm}$. The extract of the three plants presented satisfactory results in the control of the three agencies. The extract of Annona mucosa presented in all organisms analyzed average inhibitory values greater than the other extracts. All statements used in this study semonstraram great potential antimicrobials.
\end{abstract}

KEYWORDS: Plants, Medicinal, Native, Defiance.

\section{INTRODUÇÃO}

As infecções hospitalares têm sido um dos motivos mais frequentes para agravações nos quadros clínicos dos pacientes, em leitos de internações (PIMENTEL, 2012). Isso se deve a contaminação cruzada, visto que o ambiente hospitalar contribui para a alta disseminação de patógenos, por meio de pacientes já contaminados e profissionais da saúde ao não utilizarem os equipamentos de proteção individual, objetos inanimados, ou manipulações de material contaminado (PEREIRA et al., 2012).

Neste cenário pode-se salientar alguns microrganismos, devido a associação a diversas infecções hospitalares graves, como Pseudomonas aeruginosa, Staphylococcus aureus e Escherichia coli (MELLO, 2007). A bactéria Pseudomonas aeruginosa caracteriza-se pela morfologia em bastonete, sendo Gram negativo aeróbio estrito e psicotrófico (MENDES, 2014). Escherichia coli são bactérias também Gram negativas, presentes no trato intestinal da flora normal do corpo humano (COURA, 2014). Por outro lado, apresentando forma de cocos, Gram positiva estão as Staphylococcus aureus, que são bactérias com uma alta capacidade de multiplicação e disseminação (ESTEVES et al., 2014).

O mercado farmacêutico nos últimos anos tem se empenhado cada vez mais na tentativa de desenvolver antibióticos para superar estas dificuldades (BOYANOVA \& MITOV, 2010). NEWMAN \& CRAGG (2007) afirmam em seus trabalhos que, de todas as moléculas aprovadas de 1981 a 2006 pela Food and 
Drug Administration (FDA), $52 \%$ eram oriundas de produtos naturais e 18\% eram biofármacos, esses dados ressaltam a importância da busca por produtos naturais com atividade biológica.

Deste modo estudos etnobotânico surgem como um grande contribuinte para as descobertas de novos fármacos (AÑEZ, 2009). O Mato Grosso é um dos estados brasileiros que se destaca por possuir uma enorme diversidade, com a complexidade dos biomas Cerrados, Amazônico e Pantanal, o que favorece os estudos na área (CAMARGO et al., 2014). Dentre toda diversidade existente no Estado, duas famílias muito bem representadas merecem destaques: a Apocynaceae e Annonaceae, por apresentarem representantes com potencial antimicrobiano (LUZ et al., 2014; RABELO et al., 2014).

Dentro da família Apocynaceae destaca-se a espécie Aspidosperma nitidum, conhecida popularmente como carapanaúba originária da região amazônica, se caracteriza pela presença de derivados chiquimato, especialmente alcalóides e taninos (ZAGOTTA-VITAL, 2013), e pelas diversas utilizações no combate de variadas infecções como: urinária, no fígado, útero, ovário, no tratamento de problemas como diabetes, estomacais, nos rins, e também é no tratamento da malária (AÑEZ, 2009).

Já a família Annonaceae destaca-se por apresentar potencial antimicrobiano, devido a presença de princípios ativos como alcalóides e terpenoides (ALMEIDA et al., 2012). Dentro deste grupo, destaca-se o gênero Annona que no Brasil está representado por 60 espécies (CHATROU et al., 2012). Annona crassiflora é conhecida popularmente como araticum, é uma planta nativa do Cerrado brasileiro, sendo amplamente consumida nesta região devido ao aroma, sabor e valor nutritivo, com teores elevados de açúcares, proteínas e vitaminas (TELLES et al., 2003). Estudos fitoquímicos realizados nesta espécie constataram a presença de alcaloides com atividade antimicrobiana (GONÇALVES et al., 2009), evidenciando o grande potencial bactericida.

Annona mucosa é uma planta frutífera nativa e que esta distribuída por diversas regiões do Brasil, conhecida como biribazeiro (FERREIRA et al., 2010). Possuindo valor associado, uma vez que os frutos possuem aceitação popular para consumo in natura, além de características medicinais (ESTRADA-REYES et al., 2010). Deste modo, o presente trabalho objetivou avaliar o potencial antibacteriano dos extratos hidroalcoólico de Aspidosperma nitidum, Annona crassiflora e Annona mucosa, frente a Cepas Staphylococus aureus ATCC® 25923, Escherichia coli ATCC® 25922 e Psedomonas aeroginosa ATCC® 27853.

\section{MATERIAL E MÉTODOS}

O presente trabalho foi conduzido no Laboratório de Microbiologia, Centro de Pesquisa e Desenvolvimento Agroambiental (CEPEDA), da Universidade do Estado de Mato Grosso, Campus de Tangara da Serra.

Os extratos foram preparados a partir da casca de Aspidosperma nitidum, semente de Annona crassiflora e folha de Annona mucosa, todas foram limpas, com água corrente, secadas em temperatura de $37^{\circ} \mathrm{C}$ em um a estufa, e moídas com o auxílio de um moinho. Para a formulação do extrato, o pó obtido de cada planta foi submetido a percolação por sete dias, sendo utilizado como solvente o hexano 1:3. O material de cada planta foi filtrado e levado ao rotavapor, para obter-se o extrato bruto. 
Para o preparo dos inóculos bacterianos, foram utilizadas as cepas de Staphylococcus aureus ATCC 25923, Escherichia coli ATCC 25922 e Pseudomonas aeruginosa ATCC 27953. De cada cepa bacteriana foram selecionadas três a quatro colônias do microrganismo semeadas em Ágar Mueller-Hinton e transferidas para tubo de ensaio contendo solução $\mathrm{NaCl}$ estéril, foram então submetidos a diluição seriada para obter uma carga de microrganismo de $10^{-8}$ UFC (unidade formadora de colônias) $/ \mathrm{mL}$, e incubados a $35^{\circ} \mathrm{C}$ por cinco horas.

O teste de difusão em disco para avaliar a atividade antimicrobiana dos extratos foi realizado a partir da metodologia modificada de RABANAL et al., (2002) onde os discos de 6 milímetros $(\mathrm{mm})$ de diâmetro embebidos em $10 \mu \mathrm{L}$ da solução (extrato + tween). Estas diluições foram inoculadas em Ágar Mueller Hinton sobre placas de Petri, juntamente com os discos embebidos em $10 \mu \mathrm{L}$ das diluições dos extratos de Annona crassiflora, Annona mucosa e Aspidosperma nitidum. Foram realizados os fracionamentos desses extratos para obtenção de diferentes concentrações de 1:2, 1:4, 1:8, 1:16, 1:32, utilizando como diluente o Tween 20\%, para determinação da atividade antimicrobiana das plantas testadas.

Cada um dos três microrganismos foi submetido aos três extratos, sendo, cinco tratamentos por extrato com cinco repetições, de cada concentração dos extratos., constituindo, assim, delineamento inteiramente casualizado em esquema fatorial (DIC 3 microrganismos $\times 3$ extratos $\times 5$ tratamentos $\times 5$ repetições). Como controle negativo foi utilizado o Tween $20 \%$, e como controle positivo foram

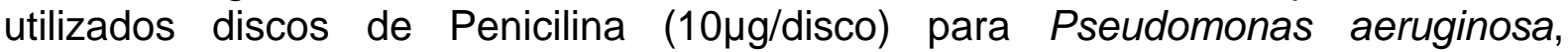

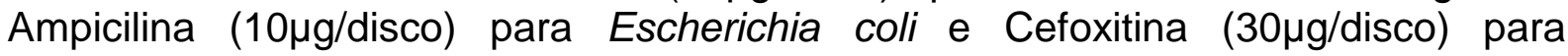
Staphylococcus aureus.

Ao término desse processo, as placas foram incubadas por 18 horas a $35^{\circ} \mathrm{C}$. Em seguida, com o auxílio de um paquímetro, foram realizadas as aferições dos halos de inibição de crescimento bacteriano. Considerando inibição da atividade microbiana as soluções que apresentaram diâmetro superiores a $8 \mathrm{~mm}$ (FERREIRA et al., 2014).

As médias foram submetidas à análise de variância (ANOVA) e ao teste de Scott-Knott à $5 \%$ de probabilidade, por meio do pacote estatístico SISVAR 5.3 (FERREIRA , 2014).

\section{RESULTADOS E DISCUSSÃO}

De acordo com os testes de média aplicados, foi possível constatar que, para o organismo $S$. aureus, o extrato de Annona crassiflora teve um maior potencial inibitório na concentração 1:2, seguido pelas concentrações 1:4, 1:8 e 1:16, as quais não apresentaram variação significativa estatisticamente, tendo um menor potencial inibitório em 1:32 (Figura 1).

Já com o extrato de Aspidosperma nitidum, houve duas concentrações que não apresentaram diferença estatística para esse mesmo organismo e se mostraram com maior potencial inibitório, sendo as diluições 1:8 e 1:32, seguidas pelas 1:2, 1:4 e 1:16 que não variaram estatisticamente entre elas. No caso do extrato de Annona mucosa para o organismo $S$. aureus, a melhor concentração encontrada foi de 1:32 seguida pela 1:8, e com um menor índice inibitório ficaram as 1:2, 1:4 e 1:16 que não apresentaram variações estatisticamente.

$\mathrm{Na}$ análise conjunta entre os três extratos para com o organismo $S$. aureus foi possível constatar que os extratos de Annona crassiflora e Aspidosperma nitidum, foram os que apresentaram maiores valores inibitórios apresentando as mesmas 
variações estatisticamente ao analisar as concentrações 1:2 de Annona crassiflora e 1:8 e 1:32 para Aspidosperma nitidum que foram as que se destacaram por apresentar os maiores valores.

\begin{tabular}{|c|c|c|c|c|c|c|c|c|c|}
\hline & \multicolumn{3}{|c|}{ Staphlylococus alureus } & \multicolumn{3}{|c|}{ Psedomonas netuginosa } & \multicolumn{3}{|c|}{ Escherichina coli } \\
\hline & A.crinsifflorll & A. nitidum & A. mulcosil & A.crilssifflorll & A. nitidium & A. mucose & A.crinsifflorll & A. nititum & A. mulcose \\
\hline $1: 2$ & $16,8 \mathrm{aA}$ & $13,0 \mathrm{bc}$ & $10,0 c D$ & $10,0 \mathrm{aB}$ & $6,0 \mathrm{aD}$ & $16.8 \mathrm{aA}$ & $10,0 \mathrm{bC}$ & $0,0 \mathrm{bE}$ & $11.8 \mathrm{aB}$ \\
\hline $1: 4$ & $14,0 b c$ & $13,0 b c$ & $12,2 \mathrm{cC}$ & $8,4 a C$ & $6,0 \mathrm{aD}$ & $13.2 \mathrm{bB}$ & $12,0 \mathrm{aB}$ & $8,4 a C$ & $14.8 \mathrm{aA}$ \\
\hline $1: 8$ & $13,8 b c$ & $18,0 \mathrm{aA}$ & $13,2 \mathrm{bC}$ & $4,66 \mathrm{D}$ & $3,26 \mathrm{D}$ & $11.4 \mathrm{bB}$ & $13,8 \mathrm{aA}$ & $9,0 \mathrm{aC}$ & $14.0 \mathrm{aA}$ \\
\hline $1: 16$ & $14,6 b B$ & $14,46 \mathrm{~B}$ & $11,0 c D$ & $5,26 \mathrm{D}$ & $5,4 \mathrm{aD}$ & $11.2 \mathrm{bB}$ & $6,8 \mathrm{CD}$ & $8,6 \mathrm{aC}$ & 13.4 aA \\
\hline $1: 32$ & $12,2 c \mathrm{C}$ & $16,4 a \mathrm{~A}$ & $15,6 \mathrm{aB}$ & $5,8 \mathrm{bD}$ & $4,0 \mathrm{bD}$ & $8.6 b c$ & $6,4 C D$ & $8,8 \mathrm{aC}$ & 13.4 aA \\
\hline
\end{tabular}

FIGURA 1. Atividade antimicrobiana do extrato de Annona crassiflora, Annona mucosa e Aspidosperma nitidum frente as cepas ATCC. Médias dos halos de inibição $(\mathrm{mm})$, seguidas de mesmas letras minúsculas na comparação na coluna e letras maiúsculas na comparação entre colunas do mesmo microrganismo, não diferem estatisticamente entre si ao nível de $5 \%$ de probabilidade pelo teste de Skott-knott.

Todas as concentrações, dos três extratos testados frente a $S$. aureus, mostraram-se eficientes no controle desta espécie, tendo médias de halos de inibição variando de 18,0 a 10,0 mm. SILVA et al., (2007), em estudo da atividade antimicrobiana do extrato de Anacardium occidentale Linn. frente a $S$. aureus, obtiveram resultados similares, com halos de inibição entre 10 e $16 \mathrm{~mm}$, contudo estes halos foram observados até diluições de 1:8. Entretanto, GONÇALVES et al. (2005), ao avaliarem o potencial do extrato de Copaifera langsdorffii, que é descrito na literatura como possuidor de ação antimicrobiana, se mostrou ineficaz frente ao referido organismo. Ratificando a importância da pesquisa de novas espécies para 0 controle de Staphylococcus aureus.

Para Pseudomonas aeroginosa, o extrato de Annona crassiflora apresentou duas concentrações com maior potencial inibitório e que não apresentaram variações estatisticamente entre $\mathrm{si}$, as diluições de 1:2 e 1:4. Já as outras concentrações apresentaram em testes de média halos menores que $8 \mathrm{~mm}$. Assim como para o extrato de Aspidosperma nitidum, que mesmo apresentando um maior valor inibitório para com o organismo $P$. aeroginosa, ainda assim, o valor das médias dos halos para todas as concentrações ficaram abaixo de $8 \mathrm{~mm}$, mostrando-se ineficaz no controle deste microrganismo.

Diferentemente, Annona mucosa para com a mesma espécie apresentou, em todas as médias, valores maiores que $8 \mathrm{~mm}$, tendo como melhor concentração a 1:2, seguida pelas 1:4, 1:8 e 1:16, que não apresentaram variações estatística entre si, e a 1:32, demonstrando em sua avaliação os valores médios dos halos entre 16,8 a $8,6 \mathrm{~mm}$.

Nas análises dos três extratos para $P$. aeroginosa, foi possível constatar que o extrato com melhor índice inibitório foi o de Annona mucosa na concentração 1:2 
tendo os outros, em boa parte de suas concentrações valores de halos menores que $8 \mathrm{~mm}$. Como pode ser analisado nesse trabalho, o organismo Pseudomonas aeruginosa apresentou uma considerável tolerância frente aos extratos testados, tais resultados corroboram com os dados do trabalho de FERREIRA et al. (2014), onde esse mesmo organismo se apresentou tolerante ao óleo essencial de sucupira, que foi o composto alvo.

Essa dificuldade no controle desta bactéria pode ser porque esse organismo apresenta a capacidade de alterar o metabolismo energético por meio do plasmídeo possibilitando, dessa forma, maior resistência, em função de dificultar muito a penetração de compostos ativos. Outra hipótese se deve ao mecanismo de membrana dessa bactéria, a mesma possui uma proteína que funciona na membrana bombeando os compostos ativos, prejudicando-a. Isso faz com que esse composto não atinja a concentração ideal para inibir o crescimento desse organismo (DEL FIO et al, 2000).

Já para Escherichia coli, o extrato de Annona crassiflora apresentou como melhor concentração inibitória as concentrações 1:4 e 1:8 não demonstrando variações estatisticamente entre elas, seguida pela 1:2, e com os menores índices inibitórios ficaram as 1:16 e 1:32.

Com o extrato de Aspidosperma nitidum na mesma bactéria, as melhores concentrações foram 1:4, 1:8, 1:16, 1:32, não apresentando variações estatisticamente. No caso da concentração 1:2 em E. coli, não houve um resultado significativo já que a média dos halos foi igual a zero, não promovendo a inibição deste microrganismo. Já com o extrato de Annona mucosa, as melhores concentrações foram 1:4, 1:8, 1:16, 1:32, tendo a concentração 1:2, potencial inibitório, porém estatisticamente menor que as demais.

$\mathrm{Na}$ análise com os três extratos para o organismo E. coli, é possível afirmar que os melhores resultados foram os apresentados pelos extratos Annona crassiflora, na concentração de 1:8, e da Annona mucosa, nas concentrações 1:4, 1:8, 1:16 e 1:32, não havendo variações estatísticas entre elas.

Pode-se ressaltar nos testes com $E$. coli que as concentrações com os menores valores de halo, tiveram grandes variações de um extrato para outro, mostrando que no caso do extrato de Aspidosperma nitidum, na concentração 1:2 não houve crescimento de halos, e que para a Annona crassiflora os resultados que apresentaram menor halo foram os da concentração 1:16 e 1:32, menores que $8 \mathrm{~mm}$, e para Annona mucosa o menor halo foi o da concentração 1:2, apresentando halo maior que $8 \mathrm{~mm}$. Esse fato, talvez, se explique devido a bactéria ser Gram negativa e ter canais protéicos, onde esses compostos antimicrobianos irão passar e atingir a membrana, chegando dessa forma aos receptores na parece celular. No caso da E. coli a passagem desses canais só permite moléculas de até 600 daltons, fazendo com que apenas as concentrações que cheguem ao valor igual ou menor que o apresentado consiga atingir a parede celular (DEL FIO et al., 2000).

A família Annonaceae teve uma intensificação nas pesquisas ao seu respeito, devido as concentrações de compostos como acetogeninas, alcalóides e taninos com alta variedade de atividades biológicas, sendo identificada como uma família de potencialidade promissora no combate de microrganismos (VILA-NOVA et al., 2011). Segundo ARRAIS et al., (2014), estes compostos possuem elevado potencial antimicrobiano, podendo assim ser uma das explicações para os resultados satisfatórios obtidos com os dois extratos da família Annonaceae. 
Segundo SIMPSON (2013), inúmeros compostos podem ser destacados em relação a espécie Aspidosperma nitidum entre estes, alcalóide, esteroides, triterpenos e pentacíclicos, que podem ser associados a atividades anti-inflamatória, e deste modo podendo explicar, a frequência do uso dessa planta, como alternativa medicinal pela população, assim como sua eficiência nesse trabalho em apresentar uma capacidade inibitória frente aos organismos testados.

Para que seja possível um composto ativo atingir o desenvolvimento de um microrganismo é necessário que haja um sitio ativo, fazendo com que os receptores desse organismo se liguem com o outro do composto ativo, ou do antibiótico. Por esse fato fazem-se necessários estudos de novas substâncias ativas, porque devido a inúmeras mutações cromossômica, os microrganismos acabam modificando a estrutura de receptor, fazendo com que o antimicrobiano não mais se ligue , e com isso torna-se resistente a determinadas drogas (DEL FIO et al., 2000).

O controle negativo realizado com o diluente Tween 20\%, nas cepas de Staphylococcus aureus, Pseudomonas aeruginosa e Escherichia coli, não apresentou inibição em nenhuma das espécies, mostrando assim que o diluente Tween não interferiu nos resultados apresentados nos testes com os extratos. Em seu estudo BRAZÃO (2012) demonstra com Piper aduncum L. o mesmo resultado encontrado neste trabalho em relação ao controle negativo Tween, este diluente não apresentou nenhum fator de inibição sobre a cepa testada. Assim como no trabalho de SWERTS et al., (2005) que também afirmaram que o tween não causa interferência quando utilizado como diluente de uma solução.

Por outro lado os antibióticos utilizados como controle positivo se mostraram eficientes apresentando a Penicilina para com Pseudomonas aeruginosa halos com média de $27 \mathrm{~mm}$, Ampicilina para com Escherichia coli, halos com média $27 \mathrm{~mm}$ e Cefoxitina para com Staphylococcus aureus, halos com média $27 \mathrm{~mm}$. Esses dados corroboram com os apresentados neste trabalho demonstrando a importância, uma vez que os extratos mesmos sendo bruto atingiram valores de halos de inibição próximos aos apresentados pelos antibióticos comerciais.

Segundo a NCCLS (2003) os antibióticos testados como controle positivo são recomendados para as referidas espécies de Cepas presentes neste trabalho. O uso indiscriminado dessas substâncias pode trazer reação inversa do esperado, propiciando um agravo no caso.

\section{CONCLUSÕES}

Todos os extratos utilizados neste estudo demonstraram grandes potenciais antimicrobianos. Dentre os três apenas o extrato de Annona mucosa apresentou em todos os organismos analisados valores inibitórios maiores que $8 \mathrm{~mm}$.

Com isso, se faz necessário mais estudos aprofundados dos compostos ativos de cada uma dessas espécies, assim como estudos da eficiência desses compostos em diferentes partes dessas plantas, como folhas, casca, sementes e frutos, e com isso, isolar esses compostos e testar, para que deste modo se descubra novas formas de combate aos microrganismos.

Apesar das três plantas apresentarem efeitos antibacterianos, não é recomendada a utilização popular dessas plantas como medicamentos alternativos no combate de infecções, pois, mesmo possuindo atividade positiva no combate a microrganismos, ainda faz-se necessário estudos aprofundados acerca dessas plantas para avaliar como podem ser utilizadas sem que causem danos a saúde humana. 


\section{AGRADECIMENTOS}

Agradecemos ao Conselho Nacional de Desenvolvimento Científico e Tecnológico (CNPq) e a Fundação de Amparo à Pesquisa do Mato Grosso (FAPEMAT) pelo suporte financeiro.

\section{REFERÊNCIAS}

ALMEIDA, J. R. G. S.; ARAÚJO, E. C. C.; RIBEIRO, L . A.; LIMA, J. T.; NUNES, X. P.; BARBOSA, J. M. Antinociceptive activity of ethanolextract from Duguetia chrysocarpa Maas (Annonaceae). The Scientific World Journal, v. 2012, p. 1-6, 2012.

AÑEZ, R. B. S. Análise morfoanatômica das folhas e casca de Aspidosperma nitidum Behth. e Aspidosperma marcgravianum Woodson (Apocynaceae) com abordagem farmacocnóstica e etnofarmacológica. 2009. (Tese- Doutorado em Ciências Biológicas).

ARRAIS, L. G.; LYRA, H. F. S.; BATISTA, D. C. A.; COUTINHO, F. N.; SARAIVA, A. M.; PEREIRA, R. C. A.; PISCIOTTANO, M. N. C.; XAVIER, H. S.; MELO, S. J. Atividade antimicrobiana dos extratos metanólicos da raiz, caule e folhas de Croton pulegioides Baill. (Zabelê).

med. v.16 no.2 supl.1 Botucatu 2014.

Rev.

bras.

plantas

BOYANOVA, L.; MITOV, I. Geographic map and evolution of primary Helicobacter pylori resistance to antibacterial agents. Expert Rev Anti Infect Ther. v. 8, n. 1, p. 59-70, 2010.

BRAZÃO, M. A. B., Atividade do óleo essencial de Piper aduncum $L$. e seu componente, dilapiol frente a Staphylococcus spp. multirresistenteUniversidade Federal do Pará Instituto de Ciências da Saúde, Programa de PósGraduação em Ciências Farmacêutica- Belém (PA) 2012.

CAMARGO. F. F.; SOUZA, T. R.; COSTA, R. C. Etnoecologia e etnobotânica em ambientes de Cerrado no Estado de Mato Grosso. Interações, Campo Grande, v. 15, n. 2, p. 353-360, 2014.

CHATROU, L. W.; PIRIE, M. D.; ERKENS R. H. D.; COUVREUR, T. R.; NEUBIG K. M.; ABBOTT, J. R.; MOLS, J. B.; CHASE, M. W. A new subfamilial and tribal classification of the pantropical flowering plant family Annonaceae informed by molecular phylogenetics. Botanical Journal of the Linnean Society, v. 169, p. 540, 2012.

COURA, F. M. Patotipos de Escherichia coli causadores de diarreia em bezerros: uma atualização. Pesquisa Veterinária Brasileira, v. 34, n. 9, p. 811-818, 2014.

DEL FIOL, F. S.; MATTOS FILHO, T. R.; GROPPO, F. C. Resistência Bacteriana. Revista Brasileira de Medicina, Rio de Janeiro, v. 57, n.10, p. 1129-1140, 2000. 
ESTEVES, D. C.; SILVA, H. P. S.; PINTO, K. S. V. R.; SONVESSO, B. L.; KELLER, R.; RODRIGUES, M. V. P. Avaliação de conservação da viabilidade de Staphylococcus aureus e Escherichia coli sob influencia e fluidos biológicos em superfícies secas . Colloquium Vitae, mai/ago 2014, v. 6(2) p.31-42.

ESTRADA-REYES, R.; ALVAREZ, A. L.; LÓPEZ-RUBALCAVA, C.; ROCHA, L.; HEINZE, G.; MORENO, J.; MARTÍNEZ-VÁZQUEZ, M. Lignans from leaves of Rollinia mucosa, Zeitschrift für Naturforschung, Tübingen, v. 57, p.29-32, 2010.

FERREIRA, D. F. Sisvar - sistema de análise de variância para dados balanceados. Lavras: UFLA, 2014.

FERREIRA, M. G. R.; SANTOS, M. R. A.; SILVA, E. O.; GONÇALVES, E. P.; ALVES, E. U. Emergência e crescimento inicial de plântulas de biribá (Rollinia mucosa (Jacq.) Baill) (Annonaceae) em diferentes substratos. Semina: Ciências Agrárias, Londrina, v. 31, n. 2, p. 373-380, 2010.

FERREIRA, S. B.; DANTAS, I. C.; CATAO, R. M. R.. Avaliação da atividade antimicrobiana do óleo essencial de sucupira (Pterodon emarginatus Vogel). Rev. bras. plantas med., Botucatu, v. 16, n. 2, p. 225-230, 2014.

GONÇALVES, A. L., ALVES FILHO, A., MENEZES, H. W. Estudo comparativo da atividade antimicrobiana de extratos de algumas árvores nativas. Arq. Inst. Biol., São Paulo, v. 72, n. 3, p. 353-358, 2005.

GONÇALVES, M. A.; LARA, T. A.; PIMENTA L. P. S. Alcalóides oxaporfínicos da madeira de Annona crassiflora- Mart. In: REUNIÃO ANUAL DA SOCIEDADE BRASILEIRA DE QUÍMICA, 29., 2009, Águas de Lindóia. Anais. São Paulo: Sociedade Brasileira de Química.

LUZ, H. S.; SANTOS, A. C. G.; LIMA; F. C.; MACHADO; K. R. G. Prospecção fitoquímica de Himatanthus drasticus Plumel (Apocynaceae), da mesorregião leste maranhense. Revista Brasileira de Plantas Medicinais, v. 16, n. 3, p.657-662., 2014.

MELO, M. A. C. Bactérias isoladas de ponte de cateter venoso central e suscetibilidade antimicrobiana em um hospital público de Belém- PA. Revista Brasileira de Análises Clínicas, Pará, v. 39, n. 2, p. 115-118, 2007.

MENDES, F. R. Qualidade bacteriológica de ovos contaminados com Pseudomonas aeruginosa e armazenados em temperatura ambiente ou refrigerados. Ciência Animal Brasileira, Goiânia, v. 15, n. 4, p. 444-450, 2014.

NCCLS-Padronização dos Testes de Sensibilidade a Antimicrobianos por Disco-difusão: Norma Aprovada - Oitava Edição M2-A8 v. 23 No 1 Substitui a Norma M2-A7 Vol. 20 No. 1, 2003. 
NEWMAND D. J, GRAGG, G. M. Natural products as sources of new drugs over the last 25 years. Jornal of Natural Products, V. 70, N. 3., P. 461-477, 2007.

PEREIRA, L. M. ; Contaminação de cassetes radiográficos em hospital privado:uma contribuição da enfermagem. J Health Sci Inst. v.30(3); p.249-254.2012.

PIMENTEL, M. C. Prevalência das infecções hospitalares causadas por Staphylococcus aureus e sua resistência aos antimicrobianos em um hospital de Campina Grande - PB. 2012. Trabalho de Conclusão de Curso (Graduação em Farmácia) - Universidade Estadual da Paraíba, Centro de Ciências Biológicas e da Saúde, 2012.

RABANAL, R. M.; ARIAS, A.; PRADO, B.; HERNÁNDEZ-PÉREZ, M.; SÁNCHEZMATEO C. C. Antimicrobial studies on three species of Hypericum from the Canary Islands. J Ethnopharmacol, v. 81, n. 1, p. 287-292, 2002.

RABELO D. M.; PINHEIRO, M. B.; BARISONII, A.; SALOMÉ, K. S.; COSTA, E. V.; SILVAII, F. M.; CHAVES, Y. O.; BASTOS, I. S. Alcaloides isoquinolínicos e investigação das atividades antiplasmódica e antibacteriana de Guatteria citriodora (Annonaceae). Química Nova, v. 37, n. 9, p. 1453-1458, 2014.

SILVA, J. G.; SOUZA, I. A.; HIGINO, J. S.; SIQUEIRA-JUNIOR, J. P.; PEREIRA, J. V.; PEREIRA, M. S. Atividade antimicrobiana do extrato de Anacardium occidentale Linn. em amostras multiresistentes de Staphylococcus aureus. Revista Brasileira de Farmacognosia, v. 17, n. 4, p. 572-577, 2007.

SIMPSON, D. C.; Desenvolvimento e validação de metodologia analítica por clae em fase reversa para a determinação do perfil cromatográfico do extrato etanólico das cascas do caule de Aspidosperma nitidum Benth (Apocynaceae). UNIVERSIDADE FEDERAL DO AMAZONAS FACULDADE DE CIÊNCIAS FARMACÊUTICAS- 2013 (Dissertação - Mestrado em CIÊNCIAS FARMACÊUTICAS).

SWERTS, M. S.; COSTA, A. M. D.; FIORINI, J. E. Efeito da Solução Associada de Clorexidina e Própolis na Inibição da Aderência de Streptococcus spp. RPE Revista Internacional de Periondontia Clínica, v.2; p.10-16.2005.

TELLES, M. P. C.; VALVA, F. D.; BANDEIRA, L. F.; COELHO, A. G. Caracterização genética de populações naturais de araticunzeiro (Annona crassiflora Mart. Annonaceae) no Estado de Goiás. Revista Brasileira de Botânica, São Paulo, v. 26, n. 1, p. 123-129, 2003.

VILA-NOVA, N. S. ; Leishmanicidal activity and cytotoxicity of compounds from two Annonacea species cultivated in Northeastern Brazil. Revista da Sociedade Brasileira de Medicina Tropical, v. 44, n. 5, p. 567-571, 2011.

ZAGOTTA-VITAL F. A.; MORAIS, S. M.; FALCÃO, M. J.; MACHADO, L. K.; BEVILÁQUA, C. M.; COSTA, I. R.; BRASIL, N. V.; ANDRADE JÚNIOR, H. F. A morfologia da antera e políneas como ferramenta para identificação das subfamílias 
de Apocynaceae. Congresso Nacional de Botânica. Belo Horizonte, p. 10-15. Anais..., 2013. 